\title{
Contenidos gráficos generados por fotógrafos ciudadanos y publicados en los medios. El caso del fotógrafo Jacobo Méndez Díez en El País
}

Juan Carlos Gómez Muñoz | jcgomez@ucm.es

Doctorando Universidad Complutense de Madrid

Andrés Ballesteros Palencia | josballe@ucm.es

Universidad Complutense de Madrid

\section{Palabras clave}

"Fotoperiodismo"; "Intrusismo"; "Redes Sociales"; "Prensa"; "Periodismo Ciudadano"; "15-M"

Sumario

1. Introducción

1.1. Periodismo ciudadano.

1.2. El fotoperiodismo en el contexto del periodismo ciudadano.

2. Metodología.

3. Desarrollo.

3.1 Cómo se hace la fotografía.

3.2 Descripción de la imagen.

3.3 Resultado de la publicación.

4. Conclusiones.

5. Bibliografía.

6. Anexo.

\begin{abstract}
Resumen
Las manifestaciones ciudadanas del 15 de mayo de 2011 en España generaron miles de fotografías en las redes sociales realizadas por fotógrafos aficionados que mostraban la realidad del momento. El objeto de este estudio pretende analizar el valor de la imagen fotográfica en el contexto de las manifestaciones sociales, hoy día desbordado por la gran cantidad de imágenes que se publican en Internet de un mismo acontecimiento y que, gracias a los avances que ofrecen los medios sociales, son filtradas por los medios tradicionales para servirse de ellas como nuevas fuentes gráficas. El estudio del caso de la fotografía realizada en Valencia por Jacobo Méndez Díez durante las manifestaciones del 15-M y
\end{abstract} publicada en El País, nos guiará en este reciente proceso comunicativo en el que intervienen entre otros factores la calidad, la inmediatez, la veracidad y las vías de obtención de imágenes que utilizan los periódicos en papel. Tras la comparación con otros casos relacionados y la revisión bibliográfica del tema podemos comprobar que, aunque no es el proceso habitual, sí es un caso que se repite cada vez más por la propia evolución de la fotografía en la red y su implementación en los ciudadanos.

Cómo citar este texto:

Juan Carlos Gómez Muñoz, Andrés Ballesteros Palencia (2018): Contenidos gráficos generados por fotógrafos ciudadanos y publicados en los medios. El caso del fotógrafo Jacobo Méndez Díez en El País, en Miguel Hernández Communication Journal, nº (2), pp. 337 a 357. Universidad Miguel Hernández, UMH (ElcheAlicante). DOI: http://dx.doi.org/10.21134/mhcj.v0i9.263 


\section{Graphic content generated by citizen photographers and published in the media. Photographer Jacobo Méndez Díez in El País}

Juan Carlos Gómez Muñoz | jcgomez@ucm.es

Universitat Oberta de Catalunya

Andrés Ballesteros Palencia| josballe@ucm.es

Universidad Complutense de Madrid

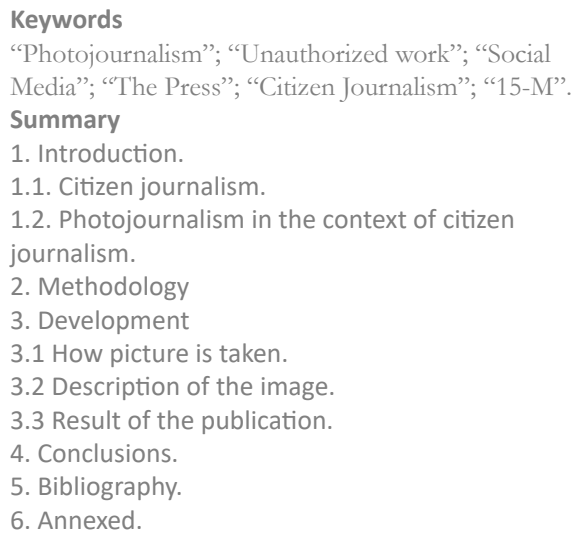

\begin{abstract}
During the May 15th 2011 public protests in Spain, lots of photographs were posted on social media. The large majority of these were taken by amateur enthusiasts and bore graphic witness to what was happening at that moment. The aim of this study is to try to analyze the value of the photographic image in the context of social unrest. Nowadays thanks to the information channels which social media provides, large quantities of this type of content are posted and are overflowing all across the internet and now serve as new sources of information
\end{abstract}

for the traditional media. A photographic case study carried out in Valencia by Jacobo Mendez Díez during the $15 \mathrm{M}$ protests provides guidelines in this recent social trial. The many different factors that come into play in these instances, the quality, the immediacy, the veracity, and the ways these images are come by and how the Press and newspapers make use of them In the wake of comparisons with other similar cases, and in line with the bibliographic review into this matter, we can check that although it is not the usual process, it will henceforth likely be the case, brought about by its own photographic evolution on the internet, and further public use.

\section{How to cite this text:}

Juan Carlos Gómez Muñoz, Andrés Ballesteros Palencia (2018): Graphic content generated by citizen photographers and published in the media. Photographer Jacobo Méndez Díez in El País, in Miguel Hernández Communication Journal, nº9 (2), pp. 337 a 357. Universidad Miguel Hernández, UMH (ElcheAlicante). DOI: http://dx.doi.org/10.21134/mhcj.v0i9.263 


\section{Introducción}

El propósito de este artículo es plantear situación de la práctica fotoperiodística digital actual a partir del estudio del caso concreto de las manifestaciones sociales del 15-M de 2011 en España. En dicha ocasión los medios tradicionales utilizaron para sus artículos y portadas fotografías tomadas de las redes sociales hechas por fotógrafos ciudadanos. Aproximarse a los cambios producidos en el periodismo gráfico tradicional, originados por el trabajo de los fotógrafos ciudadanos es el objeto principal de este artículo.

\subsection{Periodismo ciudadano}

La incorporación de los ciudadanos en la producción de contenido periodístico no debe ser vista como algo negativo, creándose un término que se ha estandarizado, periodismo ciudadano:

la participación de los ciudadanos en el ámbito informativo y, sobre todo, en el periodístico ha recibido diferentes nombres, pero en estos últimos años, la nomenclatura que mejor define este fenómeno es periodismo ciudadano o participativo, el más extendido, el que profesionales y no profesionales entienden, y el que han expuesto y argumentado profesores como Dan Gilmor, al que muchos consideramos el padre del periodismo ciudadano, además de Jay Rosen o Howard Rheingold, entre otros. (Espiritusanto y Gonzalo, 2011: 11)

Uno de los primeros aspectos que surgen al abordar el periodismo ciudadano se refiere al ya conocido debate sobre el intrusismo laboral. En esencia, los medios de comunicación y los profesionales de la información se sienten amenazados debido a la masiva y novedosa participación de los ciudadanos en la producción y difusión de información. Consideran, además, que ello conlleva una banalización de la profesión periodística en general y del fotoperiodismo en particular. Sin embargo, hay voces que defienden que no se trata ni de intrusismo ni de competencia desleal; el periodista y profesor Dan Gillmor, en una entrevista realizada en 2007 por la Biblioteca del Congreso Nacional de Chile, afirmaba que:

Este tipo de periodismo permite conocer perfectamente lo que piensan los ciudadanos y analizar cómo perciben la realidad informativa. También crea un mayor nivel de competencia y colaboración, creando ecosistemas más diversos para el periodista para mejorar la información. El periodismo ciudadano no se debe ver como una competencia, sino como un complemento (Gillmor, 2007).

El periódico Expansión recoge los datos más destacados del informe: Digital en 2018, sobre Internet y redes sociales en el mundo. En él se informa que Internet ha superado la cifra de los 4.000 millones de usuarios, lo que supone que más de la mitad de la población está conectada a la red (Yuste, 2016). Este mismo informe refleja que en España el 87\% de los ciudadanos tiene un teléfono inteligente o smartphone. Si tenemos en cuenta este último dato podemos entender que en el caso de una manifestación social son muchos los ciudadanos que pueden llegar a realizar con la cámara de su teléfono una fotografía o vídeo de lo que está sucediendo. Inevitablemente, por tanto, hay que considerar un nuevo escenario:

Las diferentes formas de participación y los numerosos y positivos cambios que vivimos actualmente en la comunicación dan una alta cuota de poder a los individuos. Medios tradicionales y periodistas se están dando cuenta de que, ahora, los ciudadanos constituyen el eslabón más importante en la cadena comunicativa (Espiritusanto y 
Gonzalo, 2011: 19).

Sin embargo, los medios parecen no terminar de aprovechar las ventajas de la evolución tecnológica y la participación ciudadana: "La interactividad le ofrece mayor poder al ciudadano pero con matices por parte de los medios, acostumbrados a una comunicación vertical con el receptor" (Fontcuberta y Borrat en Tirado, 2016). Por el contrario, Castells (2009) considera que los medios tradicionales usan las nuevas tecnologías, blogs o redes, en ambas direcciones, para mantener modos de comunicación horizontal y vertical con sus públicos.

Los ciudadanos y ciudadanas con ayuda de las tecnologías - y avalados en muchos casos por los propios medios de comunicación - se han convertido en corresponsales de la información. Uno de los casos más conocidos fue OhmyNews creado por el periodista Oh Yeon-ho en Corea del Sur y funcionando desde el año 2000 hasta 2010 con el lema: Cada ciudadano es un reportero. El proyecto tuvo ediciones en coreano, inglés y japonés y es considerado uno de los hitos pioneros del llamado Periodismo 3.0, periodismo participativo, periodismo ciudadano y también llamado periodismo democrático.

En el programa de la televisión colombiana Saber'TVer ${ }^{1}$ se emitió un reportaje, producido por la Universidad de Medellín-Colombia y realizado por el comité defensor del televidente de Teleantioquia, haciendo una aproximación a los diferentes tipos de periodismo ciudadano:

- $\quad$ periodismo ciudadano como el periodismo en el que el ciudadano participa activamente en la producción de contenido pero siempre supervisado por un periodista profesional.

- periodismo comunitario como caso del periódico hiperlocal Mi Comuna 2 (http://www. micomunados.com/) —el término periodismo hiperlocal fue acuñado por Jeff Jarvis, profesor director del programa de periodismo interactivo en la Graduate School of Journalism de la CUNY (Espiritusanto y Gonzalo, 2011: 25)—, que está gestionado por profesionales voluntarios con dinero participativo y en el que un comité de redacción de contenidos consulta a los ciudadanos los temas que quieren que se publiquen en el periódico. Además, se realizar una capacitación técnica a los ciudadanos para que participen de forma adecuada y activa en este proceso comunicativo.

- periodismo participativo como el periodismo en el que los ciudadanos mismos producen el contenido; pero no hay ayuda, ni filtro profesional y lo asocian a la movilización en las redes sociales.

Sin embargo, hay que mesurar la aportación del periodismo ciudadano en su justa medida y más bien considerar su contribución como un complemento a los medios profesionales debido a que "los ciudadanos no tienen ni el deber, ni el compromiso ni las posibilidades de acceso a la información que les permitan cumplir a cabalidad con la responsabilidad social que define al periodismo" (Puente, Saavedra y Grassau, 2011).

Los conceptos de periodismo ciudadano y periodistas ciudadanos han llegado ya hasta la ONU, lo cual es un indicador de la importancia y consideración del fenómeno a nivel internacional. Frank La Rue, portavoz especial para la promoción y protección del derecho a la libertad de opinión y expresión de la ONU, presentó, en la 65a sesión de la Asamblea General, la necesidad de protección de los periodistas ciudadanos ${ }^{1}$ : «Dado que, por su carácter, los periodistas ciudadanos están más aislados y son más vulnerables a las agresiones que los periodistas profesionales» (Espiritusanto y Gonzalo, 2011: 19).

${ }^{1}$ Diferencias entre Periodismo ciudadano, participativo y comunitario. SaberTVer. Publicado el 9 nov. 2015. Disponible en: https://youtu.be/8cwVnInk_dc 


\subsection{El fotoperiodismo en el contexto del periodismo ciudadano}

La actualidad informativa exige a los medios tradicionales una adaptación casi obligatoria con los nuevos canales informativos para competir en el mercado. En el ámbito fotográfico, cada vez más, los periódicos y revistas publican imágenes realizadas por personas no profesionales en el mundo de la fotografía. Se puede considerar un profesional de la fotografía a la persona que vive del oficio, que está técnicamente preparada, normalmente con estudios en la materia, que tiene el equipo necesario y que está acreditado por alguna asociación o medio que le respalda en su labor diaria —además si trabaja como autónomo, debe declarar al Ministerio de Hacienda sus ingresos por las fotografías vendidas-.

Hoy día el perfil del fotógrafo ha cambiado. Ahora no necesariamente se tienen que cumplir todos los requisitos anteriores para conseguir una publicación en un medio de comunicación. La revolución que ha supuesto Internet _ “....es uno de los inventos más notables de la humanidad. En términos de impacto social, ostenta el mismo rango que la imprenta, el ferrocarril, el telégrafo, el automóvil, la energía eléctrica y la televisión” Crystal (2002: 306)— ha transformado también el sistema de publicación de fotografías. En la era de la web 2.0 los medios utilizan las redes sociales como fuente de imágenes y videos.

La proliferación de imágenes en las redes también ha sido enormemente impulsada porque las cámaras fotográficas se han convertido en un elemento común de entretenimiento para los ciudadanos —además de su rápida adaptación a los móviles y dispositivos electrónicos que han hecho accesible la fotografía no solo entre los aficionados y especialistas sino a toda la ciudadanía - Practicar fotografía en estos tiempos es relativamente fácil: las cámaras digitales se han abaratado y han evolucionado de tal manera que es posible realizar cuantas fotografías se desee de un mismo instante con rapidez, gran calidad y de manera manual o automática.

Nada comparado con el costoso sistema de producción analógico anterior a la aparición de la fotografía digital. Las cámaras de película estaban limitadas por el número de fotografías que contenía el carrete; por ejemplo, 24 o 36 exposiciones —un sistema además limitado porque no permitía ver la fotografía realizada hasta su revelado en el laboratorio-, a diferencia de hoy día cuando no solo es posible verla, sino corregirla y publicarla en Internet en cuestión de minutos.

La práctica del fotoperiodismo actual presenta nuevos actores en la escena mediática y, aunque deberían ampliarse los conceptos adecuándose a la propia evolución social y tecnológica del oficio, sigue siendo válida la definición que hizo hace más de 40 años Wilson Hicks, editor gráfico de la revista Life, subrayando la imprescindible conexión entre texto e imagen en la pieza periodística: "Esta particular integración de los medios verbales y visuales de comunicación es, en una palabra, fotoperiodismo" (Hicks, 1972: 19).

Con respecto a las fotografías publicadas en prensa y con el objetivo de aproximarnos al fotoperiodismo actual, podríamos cuestionarnos a quién se puede considerar como un fotoperiodista profesional: ¿un periodista que no es fotógrafo, pero que en un momento puntual realiza y publica una foto?, o en el caso de los fotógrafos que no han ejercido ni estudiado periodismo, si es correcto en ambos casos llamarles fotoperiodistas por el mero hecho de haber publicado una fotografía.

Martínez Moscoso (2002: 140) refiriéndose al discurso, considera que durante la ejecución del 
acto fotográfico son cuatro los elementos que actúan y dejan huella en el objeto simbólico en que se constituye la fotografía de prensa:

- metadiscurso de objetividad y realismo.

- la aparente ausencia de códigos.

- la necesidad de plasmar elementos informativos.

- la pretensión estética.

La labor del fotógrafo en los años anteriores a la llegada de la fotografía digital era realizada en su gran mayoría por profesionales. Los aficionados o amateur en contadas ocasiones conseguían una publicación en un periódico, únicamente en el supuesto que el medio en cuestión no tuviera un fotógrafo en el lugar de los hechos y necesitara utilizar estas fuentes alternativas. Hoy en día el trabajo del fotógrafo se ha diversificado, ya no solo porque además de fotografías se pueden realizar vídeos con el mismo dispositivo sino por la aparición de nuevos fotógrafos, aficionados o nuevos profesionales en la escena mediática.

Sin embargo, es preciso aclarar que no es lo mismo registrar o grabar un archivo gráfico que publicarlo en las redes sociales. Si lo guardamos en la memoria del móvil, la tarjeta de la cámara o el disco duro del ordenador y no lo publicamos, lo convertiremos en un archivo personal y no público, como ocurre con las publicaciones de fotografías en las redes sociales y dependiendo quién, cuándo y dónde las publique tendrán más o menos visibilidad en la red.

También está claro que aunque que gran parte de los ciudadanos disponen de aparatos de registro gráfico, no todos saben realizar fotografías o vídeos respetando unos mínimos de calidad técnica y estética para publicar sus imágenes. A pesar de ello, cuando se trata de una noticia relevante y no se cuenta con ninguna otra fotografía realizada por un profesional, los medios utilizan las fuentes ciudadanas ya que se consideran excepciones donde prima el valor informativo sobre la calidad técnica y estética (De Pablos, 2006).

Uno de los primeros ejemplos — considerado el primer ejemplo de reporterismo gráfico ciudadano- ocurrió en 1991 con la filmación inédita que realizó George Holliday grabando la paliza que la policía le dio al ciudadano negro Rodney King en Los Angeles con su cámara de video casera; y que posteriormente fue publicada por la cadena de televisión local de Los Ángeles KTLA (Ximénez, 2017). Un ejemplo español reciente tuvo lugar cuando el periódico El País publicó en su web el vídeo grabado por un taxista con su móvil en el que se ve, a gran distancia de los hechos, cómo aficionados ultras del Atlético de Madrid lanzan el cuerpo de un ultra contrario del Real Club Deportivo de La Coruña al río Manzanares en Madrid (Ortega, Moñino y Pregedo, 2014). Sobre el mismo suceso, El País publicó en su portada del 1 de diciembre de 2014 un fotograma con baja calidad de otro video grabado por un vecino desde su ventana durante los incidentes en la zona de Madrid Río (ver figura 1).

En la fotografía de prensa actual hay fotógrafos profesionales que trabajan como freelance y se dedican a buscar imágenes a diario para vender su trabajo a los medios; en algunos casos compitiendo con fotógrafos aficionados que aprovechan el hecho de disponer de cámaras y tecnología para intentar publicar su trabajo — aunque en la mayoría de los casos no se trate de un material buscado sino producto de situaciones casuales que se presentan-.

Normalmente las imágenes de los ciudadanos publicadas en los medios acaban siendo filtradas y seleccionadas por los editores gráficos buscando las más destacadas y las de mayor calidad. 


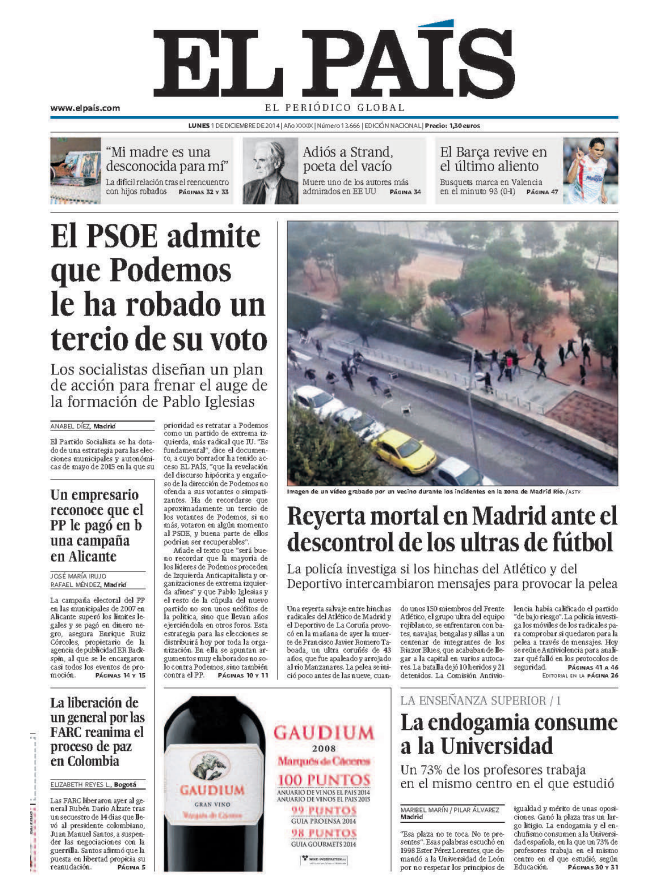

Figura 1. Portada de El País, 1 de diciembre 2014. Fuente: El País. https://goo.gl/aKeXSB

En estos casos se abre otro debate: la compensación económica que reciben (o deben recibir) los ciudadanos por su trabajo gráfico realizado, en comparación con el pago habitual a los profesionales, sean de plantilla o freelance. Habitualmente, los medios de comunicación hacen un pago muy inferior por las fotografías y vídeos adquiridos a los fotógrafos ciudadanos, amparándose en su menor calidad y en el hecho de que los ciudadanos no están acreditados como profesionales.

Los ciudadanos, a diferencia de los fotógrafos profesionales de los medios, utilizan como medio de distribución de sus imágenes los blogs y redes sociales (Facebook, Flickr, Twitter, Instagram...) modificando el proceso tradicional en el que las imágenes llegaban al público. Estas fotografías deben comprobarse por los editores gráficos de los medios — con herramientas como Google Imágenes - para ver si han aparecido antes en Internet o tienen algún montaje, en definitiva, rastrear su veracidad. Este nuevo escenario mediático conlleva una perspectiva completamente nueva acerca de la fiabilidad de las fuentes de información y la necesidad de la verificación:

Los periodistas ciudadanos necesitan, además, entender la importancia de la verificación, de la disponibilidad de múltiples perspectivas de la misma historia y de la capacidad para contar esa historia. El desafío no consiste solo en mantenerse al día con las tecnologías. El desafío, para los profesionales y los aficionados, consiste en entender la importancia de la búsqueda de la verdad a la hora de informar acerca de una noticia y el papel fundamental del periodismo en la democracia. (Howard Rheingold en Espiritusanto y Gonzalo, 2011: 19)

No obstante, no solo el periodismo ciudadano necesita ser filtrado y comprobado puesto que en el periodismo profesional también se han dado situaciones en las que se ha faltado al rigor 
deontológico. Como en el caso del fotógrafo Brian Walski, que fue despedido en 2003 de Los Angeles Times por realizar un fotomontaje con dos de sus fotografías de la guerra del Golfo, llegando a engañar a su propio medio (Reuters, 2003).

En 2008, Turi Munthe crea Demotix, una agencia de fotografía alternativa basada en las colaboraciones de periodistas ciudadanos y freelances capaces de llegar allí donde no lo hacen los periodistas tradicionales. En dos años consiguieron llegar a vender imágenes a los medios internacionales más importantes del mundo; aunque su aventura terminó en 2012 cuando fue adquirido por la multinacional Corbis. El propio Munthe consideraba que la labor de los aficionados debía ser apoyada por profesionales: "solo puede funcionar cuando hay profesionales que están ahí para ayudar a los ciudadanos, completar sus informaciones, contextualizarlas y verificarlas" (Munthe en Molina, 2011).

Sin embargo, conviene recordar que la participación ciudadana en la generación de contenido utilizado por los medios es algo que forma parte de la historia del periodismo. La Biblioteca del Congreso de los Estados Unidos comparte actualmente en Flickr parte de su depósito fotográfico con el fin de que el público pueda añadir comentarios y etiquetarlas. Una parte de su catálogo es la Colección Bain ${ }^{1}$, una de las primeras agencias de noticias y fotografía: Bain News Service, fundada en 1898 por George Grantham Bain ${ }^{3}$ y centrada especialmente en la ciudad de Nueva York. Esta agencia de noticias es un ejemplo pionero al incluir la participación ciudadana como medio para mejorar su archivo fotográfico:

George Grantham Bain fundó el primer servicio de fotografía de noticias en 1898 en la ciudad de Nueva York. Acumuló fotografías de cobertura mundial que se distribuyeron en varios periódicos. El servicio de noticias Bain mejoró al recibir imágenes locales de sus suscriptores de periódicos como parte de su reembolso (Library of Congress) ${ }^{4}$.

Los fotógrafos profesionales ya no son solo reporteros que toman imágenes, ahora otra de sus funciones consiste en verificar la información e imágenes que llegan a la audiencia a través desde los fotógrafos ciudadanos. Es decir, convertir en fuentes fiables el aluvión de imágenes que llegan a diario a las redacciones gráficas.

Así, son objeto de nuestro estudio los cambios surgidos en este nuevo proceso comunicativo debido a la participación de los ciudadanos y, concretamente, los fotógrafos en los movimientos sociales, planteándose las siguientes preguntas:

- ¿pueden coexistir fotógrafos profesionales y fotógrafos ciudadanos?

- ¿pierden o ganan calidad las publicaciones con estas nuevas fuentes de información?

- ¿pierden o ganan credibilidad los contenidos gráficos surgidos por fotógrafos ciudadanos no profesionales?.

\section{Metodología}

La metodología se basa en la revisión bibliográfica del tema y un análisis de caso, donde además se han repasado casos similares que hacen una aproximación al tema propuesto. Además se completa con la técnica cualitativa mediante una entrevista realizada a Jacobo Méndez Díez, el fotógrafo objeto de nuestro estudio ${ }^{5}$. "Cuando se realiza una investigación social basada en entrevistas, al margen de otros objetivos de investigación, se plantea la cuestión sobre cómo ocurrieron las cosas 'en realidad"” (Ballester, Orte y Oliver, 2003: 143).

${ }^{3}$ Pueden consultarses los datos de la colección y el enlace a Flickr aquí: http://www.loc.gov/ pictures/collection/ggbain/?loclr=flik

${ }^{4}$ Library of Congress. Bain News Service photograph collection. Disponible en: https://www.loc. gov/pictures/item/2005682517/

${ }^{5}$ La entrevista completa puede consultarse en el Anexo final. 
Jacobo Méndez es un fotógrafo madrileño residente en Valencia y autor de la fotografía que El País publicó en su portada de papel el día 20 de Mayo de 2011. En la instantánea se aprecian unos activistas del 15-M procediendo a poner una letrero adhesivo sobre el nombre de la plaza del Ayuntamiento con el nombre Plaça del Quince de Maig. La entrevista fue realizada vía telefónica el 18 de marzo de 2018.

La elección de la fotografía de Jacobo como caso de estudio explica el proceso comunicativo que puede seguir la imagen de un fotógrafo ciudadano (publicada primero en redes sociales), hasta llegar a ser portada de un periódico tradicional producto de la casualidad del momento, unido a la buena técnica aplicada por el fotógrafo y, tal vez, el mejor punto de vista para la situación que presentaba la escena en el instante de la toma. La atención informativa durante el periodo del 15-M se caracterizó por la importancia que los ciudadanos concedieron a las redes sociales. La imagen nos sirve para mostrar cómo ha contribuido el fenómeno del llamado periodismo ciudadano a la transformación de la comunicación.

\section{Desarrollo}

El Movimiento 15-M fue una manifestación ciudadana que nació el 15 de Mayo de 2011 en la Puerta del Sol de Madrid (España), donde los ciudadanos protestaron por la situación de crisis económica que vivía el país, señalando las políticas del gobierno como responsables del malestar social:

Al término de aquella movilización se produjeron algunas cargas y detenciones policiales, en protesta por lo cual algunas decenas de manifestantes decidieron quedarse a "acampar" en el kilómetro 0 madrileño. Lo que parecía una iniciativa de escaso recorrido, se convirtió en una movilización multitudinaria con el mayor impacto en la política española de las últimas décadas[...] cuando el 18 de mayo la Junta electoral central prohibió las concentraciones en Sol por la cercanía de las elecciones municipales y autonómicas, tuvo el efecto opuesto al buscado. Durante ese fin de semana y los días sucesivos la toma de plazas se había extendido por todo el territorio del estado español, con especial fuerza en Barcelona, Valencia o Sevilla (Errejón, 2011).

Durante estas manifestaciones en diferentes ciudades de España, personas de todas las edades eran convocados a través de las redes sociales, con la atenta mirada de los medios de comunicación. En este contexto, el periodismo ciudadano y los fotógrafos ciudadanos tuvieron un lugar importante en la narrativa de los detalles que rodearon este acontecimiento. En las redes sociales los ciudadanos ejercieron una labor participativa y comunicativa informando sobre lo que estaba sucediendo y publicando multitud de fotografías y vídeos.

Nuestro caso de estudio se centra en la fotografía realizada por el ciudadano madrileño de 44 años Jacobo Méndez Díez; fotógrafo aficionado que el 20 de Mayo de 2011 realizó una instantánea en la plaza del Ayuntamiento de Valencia y al día siguiente de publicarla en Internet fue portada en el El País. Un año después recibiría el Premio Ortega y Gasset de periodismo gráfico por esta imagen: “'recoge como pocas el espíritu del movimiento’. El jurado reconoce el gran simbolismo de la foto que representa ‘todo un fenómeno que va más allá de lo cultural y lo social. Tiene una composición clásica dentro de la espontaneidad del movimiento"”.

Si la foto no hubiera tenido gran valor (no solo técnico y estético sino también comunicativo)

${ }^{6}$ El País (2012). Periodismo que se nutre de la calle. En El País.com (19/04/2012) Disponible en: https://goo.gl/QLuKQB 
tal vez no hubiera pasado de incluirse como una breve fotonoticia, un género que si bien se caracteriza por destacar la imagen acompañada de muy poco texto (Castellanos, 2011), no alcanza la relevancia de la noticia y el reportaje y, habitualmente, no llega a ser portada de un diario.

\section{EL PAISS}

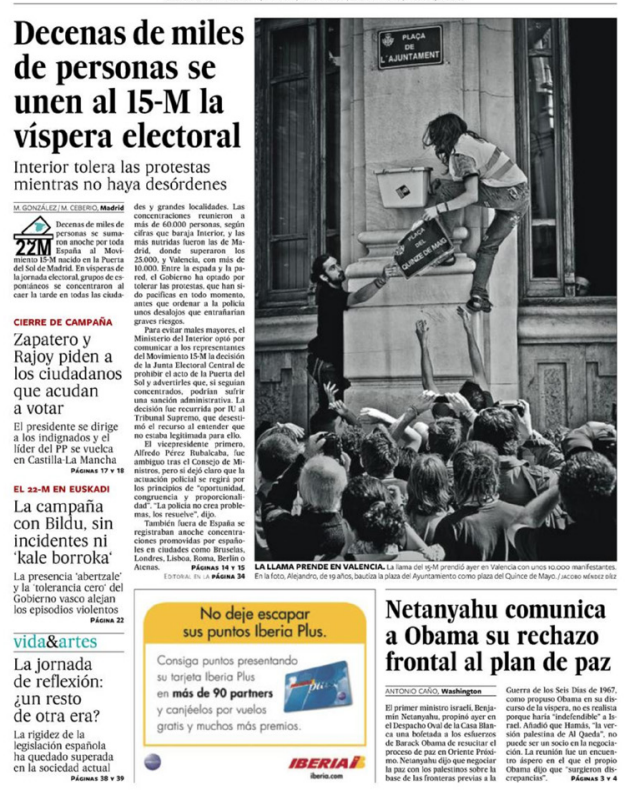

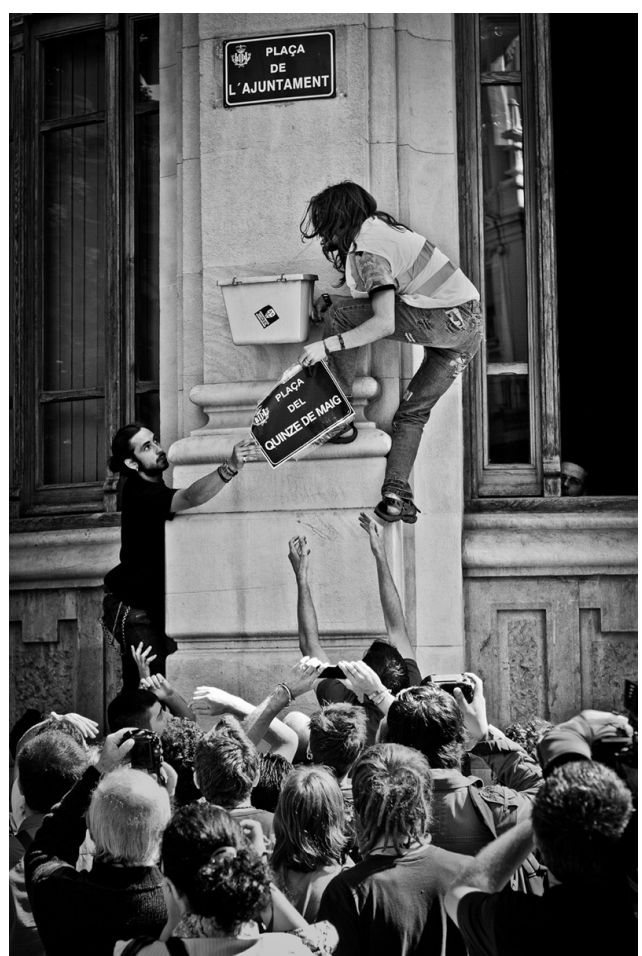

Figura 1. Fotografía de Jacobo Méndez y Portada de El País (21/05/2011). Fuente: El País. https://goo.gl/63Qv3R

\subsection{Cómo se hace la fotografía}

Según el autor de la fotografía (Méndez, 2018), cuando tenía 19 años colaboró como fotógrafo de prensa en El Salvador donde pasó su infancia y adolescencia con su padre, también fotógrafo y publicista de quien heredó el arte y la pasión por la fotografía de prensa, coincidiendo con la Guerra civil Salvadoreña. Méndez explica que en la época en la que ocurrió el 15-M se encontraba en situación de desempleo y, sabiendo el ambiente político que acontecía, se le ocurrió que sería un gran día para hacer fotos. Salió a la calle con su cámara el 20 de mayo de 2011 y se dirigió hacía el centro de la ciudad.

Recuerda que al día siguiente eran las elecciones y solo fue a hacer fotos por placer; mientras estaba en la Plaza del Ayuntamiento se fijó en un grupo de jóvenes que iban caminando con una placa adhesiva en la mano (similar en color y tamaño a la que reza en las calles del ayuntamiento), escrita en valenciano, en la que se podía leer Plaça del Quinze de Maig, [Plaza del Quince de Mayo]. Les siguió hasta que se empezaron a trepar en la pared del edificio del ayuntamiento y cuando vio la situación, tomó distancia de la escena, hizo unas cuantas fotos, "siete aproximadamente, no muchas", porque como dice, no sufre del "Síndrome de Diógenes en la fotografía" (Méndez, 2018). Ha afirmado que no le gusta disparar fotografías en ráfagas porque se considera fotógrafo de los de antes, de revelado en el laboratorio, "cuando los carretes costaban y había que revelar, 
y no podías hacer más de las fotos que las te daba el carrete” (Méndez, 2018).

El autor nos describió los siguientes pasos que llevó a cabo para publicar su fotografía: después de hacer la foto, la descargó al ordenador, seleccionó la que mejor consideraba, en la edición solo le ajustó el color y la pasó a blanco y negro, no le hizo ningún recorte ni montaje y la compartió en Facebook. Como vio que no tuvo mucha repercusión y creyendo que era una foto importante se le ocurrió subirla a Twitter. Para ello primero creó una cuenta en Flickr (con el fin de alojarla en este banco de imágenes) y antes de publicar el enlace de la fotografía en Twitter le escribió a un conocido tuitero (@kurioso) con miles de seguidores con el que ya había hablado un par de veces pidiéndole si la podía retuitear para que la viera mucha gente. Una vez que la fotografía fue retuiteada por este perfil la foto se hizo viral, y en solo una hora ya tenía 10 mil visitas en Flickr con felicitaciones por la imagen.

Posteriormente empezaron a contactarle a través de Twitter varios periódicos entre ellos el diario El País, medio al que Jacobo respondió con una llamada a la redacción gráfica y donde se alegraron de encontrarle pues consideraban que su fotografía era la foto que estaban buscando para la portada del día siguiente (sábado 21 de Mayo 2011). Llegaron a un acuerdo económico sorprendiéndole la escasa cantidad de dinero ofrecida por el medio-. Además, le propusieron colaborar con ellos y continuar en contacto con la redacción gráfica si tenía mas instantáneas para vender.

Durante esta entrevista el autor nos resumió las características técnicas de la imagen: para las aproximadamente siete fotos que hizo utilizó una cámara Canon EOS 20D con un objetivo fijo de distancia focal 50mm, f/1,8, enfoque manual, ISO 100 y una velocidad alta para congelar el momento.

\subsection{Descripción de la imagen}

En la imagen se pueden apreciar tres acciones y puntos de interés: -Los jóvenes que están trepando la pared con la placa adhesiva en la mano.

-La mirada de el hombre que está en el interior del ayuntamiento.

-La gente que se encuentra observando y registrando la situación.

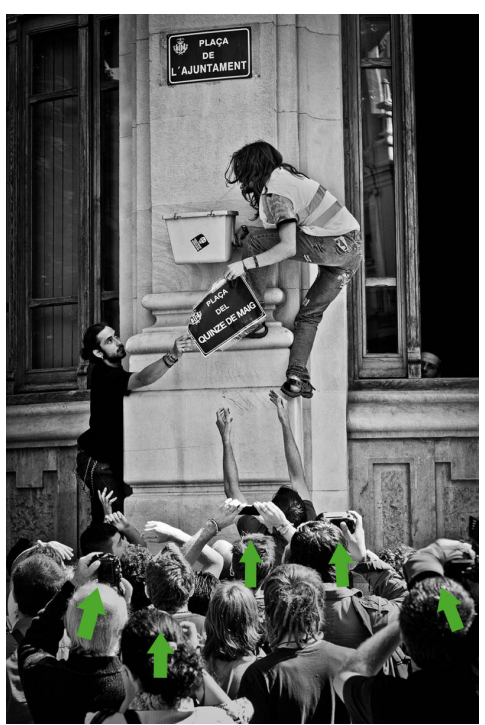

Figura 2. Las flechas señalan a otros fotógrafos aficionados tomando la misma acción. Elaboración propia. 
Jacobo Méndez destaca el número de fotógrafos ciudadanos (ver figura 2) que en ese mismo momento también estaban registrando la escena: desde distintos puntos de vista, con distintas cámaras y teléfonos inteligentes; pero tal vez Jacobo fue el que con más calidad, nitidez, encuadre, y rapidez lo hizo y con el punto de vista más acertado.

Para captar este tipo de imagen es importante la experiencia y preparación del fotógrafo, el equipo; pero además, para llegar a los grandes medios, en este caso fue necesaria la adecuada publicación en las redes sociales. Probablemente si Jacobo no hubiera compartido su foto en Twitter —y no hubiera sido retuiteada con el impulso de@kurisoso—no habría llegado a ser vista con tal rapidez por los medios tradicionales.

En el contexto en el que se encontraba Jacobo entendió que los jóvenes manifestantes que aparecen en su imagen iban a realizar una acción retratable. Se trataba de un acto simbólico y el resultado fotográfico y su publicación en El País ejemplifica la combinación del auge de los movimientos sociales a través desde el periodismo ciudadano. Podemos ver representado, por un lado, a los fotógrafos ciudadanos con la fotografía de Jacobo Méndez, y por el otro, a los medios de comunicación tradicionales con la publicación en papel del periódico El País.

El proceso de obtención de imágenes para los periódicos tradicionales antes de la llegada de la fotografía digital a los ciudadanos se nutría de imágenes o material gráfico en su gran mayoría procedente de fotógrafos profesionales freelance, fotógrafos de plantilla o agencias internacionales de fotografía como Associate Press (AP), Agencie France Press (AFP), Reuters o la Agencia Efe en el caso de España. Exceptuando casos muy puntuales que no llegaban a cubrir los medios.

Este estudio refleja además una aproximación de las recientes fuentes gráficas que disponen hoy los medios de comunicación en las redes sociales y del filtro o los criterios de selección entre la gran variedad de instantáneas que se pueden producir de un mismo acontecimiento. En este caso estamos hablando de imágenes provenientes de fotógrafos ciudadanos en manifestaciones sociales en las que destacan la calidad de las instantáneas, las veces que se haya compartido o reproducido, y en general el proceso viral que haya seguido en los medios sociales hasta llegar a ser vista por un periódico tradicional.

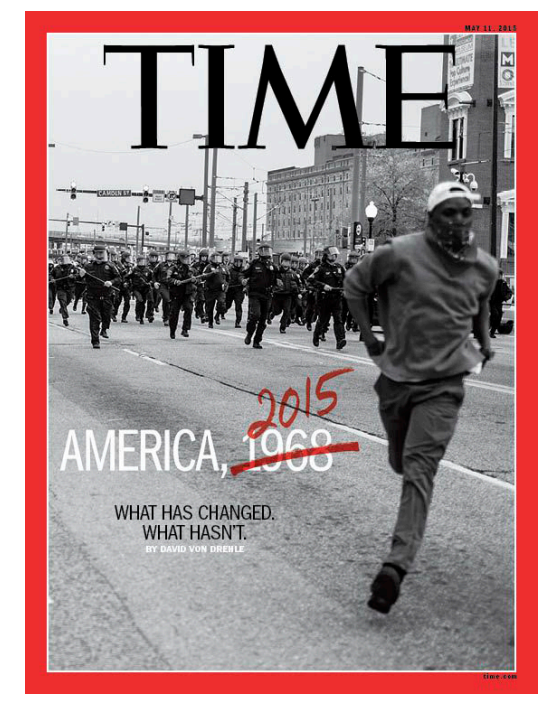

Figura 3. Time 11 mayo 2015. Protestas en Baltimore, EEUU. Fuente: https://goo.gl/Djp9Pn 
Este proceso que vivió en las redes sociales la fotografía realizada por Jacobo hasta llegar a un periódico tradicional no es la primera vez que ocurre; pero sirve de ejemplo para ejemplificar este proceso comunicativo. Un caso similar tuvo lugar unos años después en EEUU. Devin Allen, fotógrafo aficionado de 26 años que cubrió las manifestaciones de Baltimore en Estados Unidos en 2015, publicó en Instagram una imagen que se hizo viral. Posteriormente la revista Time se puso en contacto con él para publicarla en la portada con el objeto de reflejar el malestar social en EEUU.

\subsection{Resultado de la publicación}

La figura 4 recoge el proceso que llevó la fotografía de un aficionado a la portada del medio impreso con mayor tirada en España:

- Fotografía realizada 15-M Valencia: Ciudadano / Jacobo Méndez (20 Mayo-2011).

- Edición fotográfica (Cambio a B/N) - Facebook y Redes Sociales/ Flickr, Twitter).

- Miles de visitas Internet: Usuarios en las redes sociales.

- Filtrada por los medios: El País, y otros medios.

- Propuesta de compra: Fotógrafo Ciudadano vs Medios.

- Publicación en portada de papel: (El País, 21 de Mayo de 2011).

- Premio Ortega y Gasset: (Premio al Periodismo Gráfico, abril de 2012).

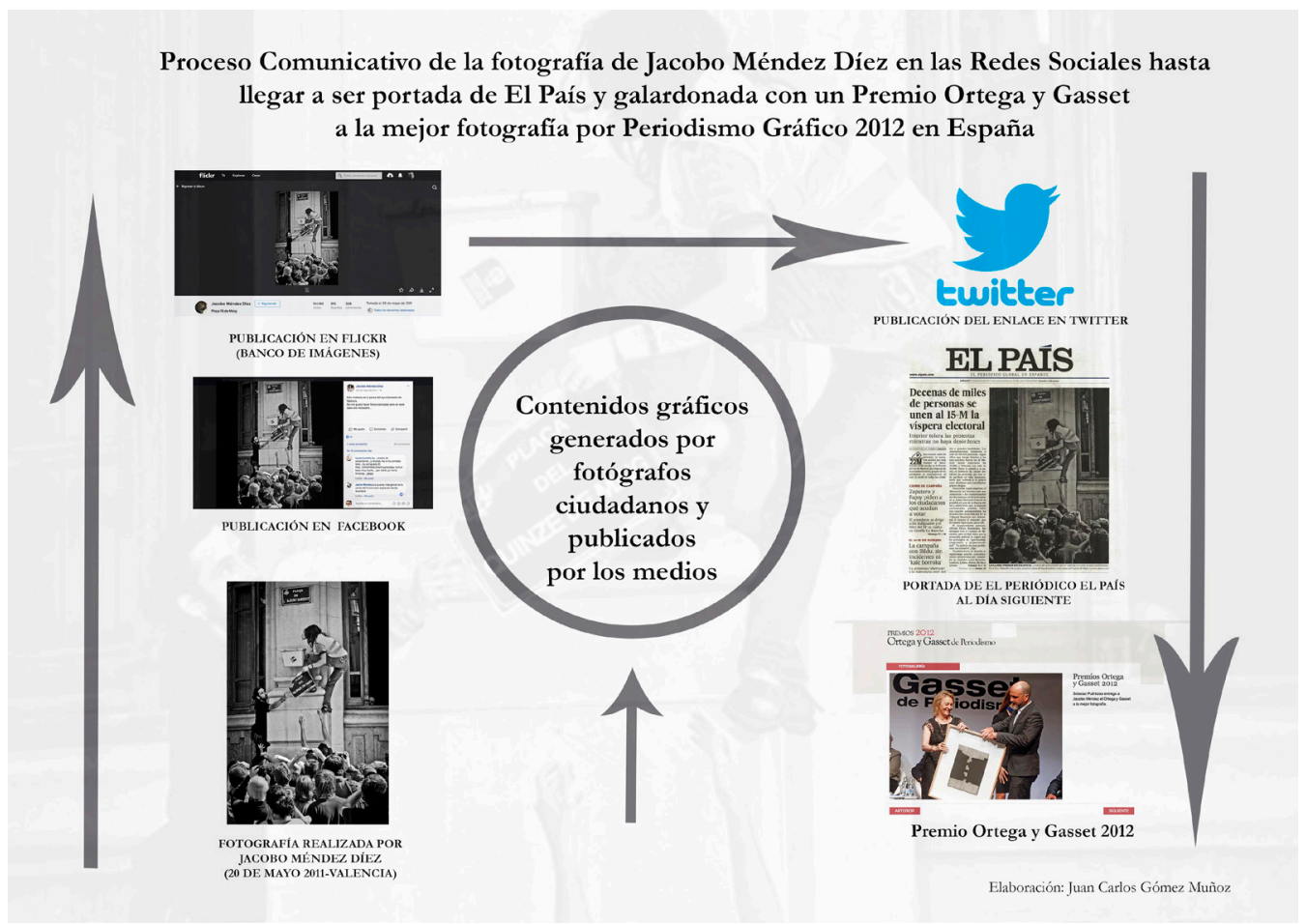

Figura 4. Gráfico del proceso comunicativo. Fuente: Elaboración propia

Es un proceso que se repite a diario en todo el mundo en manifestaciones y acontecimientos que cubren tanto los profesionales acreditados como los fotógrafos ciudadanos. En el caso de la fotografía objeto de nuestro estudio son varios los factores que intervinieron para su éxito: 
el momento de la toma, la situación, el punto de vista, la distancia, el objetivo utilizado, tener el equipo preparado con los parámetros adecuados de la cámara, la experiencia del fotógrafo y la rapidez para gestionar el archivo gráfico en las redes sociales, apoyado por un perfil de Twitter con muchos seguidores.

Esa misma acción fue captada por muchos otros ciudadanos con sus dispositivos móviles, no necesariamente cámaras fotográficas, y algunas llegaron a publicarse en otros medios (ver fig. 5). Sin embargo, al mirar estas otras imágenes, es fácil comprobar que no tienen la potencia de la imagen que fue portada de El País. La experiencia y pericia del fotógrafo fueron determinantes para obtener una imagen de amplio alcance y repercusión. El autor afirma: "este tipo de fotografía, la buscas, hay una intención cuando haces una foto" (Méndez, 2018). Cree que tuvo el acierto de seguir a los jóvenes y esperar su actuación para capturar esta instantánea que califica con un estilo de composición renacentista y casi barroca.

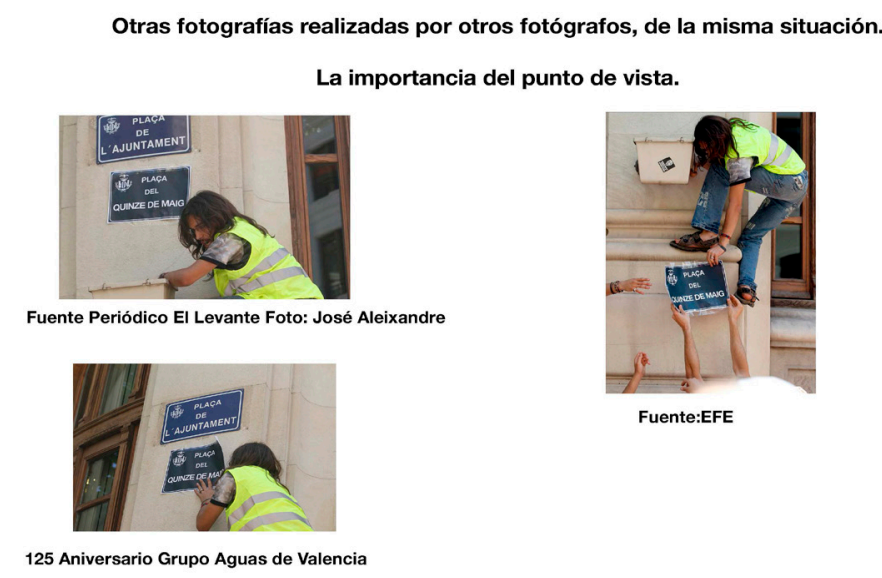

Figura 5. La misma acción publicada en otras fuentes, comparativa de puntos de vista. Fuente: Elaboración propia a partir de: https://goo.gl/aRj1yQ

Jacobo Méndez cree que la aportación ciudadana es muy positiva. Sostiene que "antes opinar era muy difícil" (Méndez, 2018), por ello afirma que lo bueno que tienen las redes sociales es que todo el mundo puede participar activamente y aportar algo. Cree que él ha podido aportar un granito de arena en algo que le apasiona; pero aclara que aunque él hizo una foto periodística no se considera periodista. Durante la entrevista afirma que es fotógrafo por amor al arte y no se define como fotoperiodista solo por el hecho de haber tomado esta fotografía: "le parecería muy vanidoso meterse en el grupo de fotoperiodistas solamente por haber recibido un premio, cree que detrás de un fotoperiodista profesional hay mucho esfuerzo, mucha carrera y muchas horas de calle, se considera un fotógrafo amante del papel y el blanco y negro" (Méndez, 2018). Jacobo afirma que después ver su fotografía publicada en la portada de El País siguió su vida con normalidad pero que finalizando ese mismo año, se animó a participar con la imagen del 15-M, en los Premios Ortega y Gasset. Emocionado señala que meses después se pusieron en contacto con él para informarle que su instantánea había sido galardonada con el Premio Ortega y Gasset de Periodismo Gráfico 2012. 


\section{Conclusiones}

La entrevista a Jacobo Méndez expone cómo un fotógrafo ciudadano - aunque técnicamente un profesional por su experiencia como fotógrafo de prensa en El Salvador- no fue a la manifestación del 15M en Valencia con el objetivo de realizar una imagen para vender a ningún medio. Este caso sugiere una reflexión sobre la identidad de los fotógrafos hoy, sean profesionales o ciudadanos, que llegan a publicar en los medios. Consideramos que la calidad fotográfica de la imagen califica el estilo pero no la profesión. La publicación de fotografías ciudadanas en portadas de medios tradicionales, aunque no es un proceso habitual, sí es algo que se repite cada vez más, probablemente por la propia evolución de la fotografía en la red, además de la rápida actuación de los medios para adaptarse al mercado.

La comunicación en las redes sociales ofrece a los medios nuevas fuentes gráficas variadas y más económicas; pero que deben filtrarse adecuadamente para elegir las mejores instantáneas, con el objeto de competir en el mercado actual y combatir la llamada crisis del papel derivada de la expansión digital. La difusión de imágenes viralizadas en la red amplía los recursos gráficos para los medios, creando nuevos procesos comunicativos en el periodismo y entre los ciudadanos.

Respondiendo a las preguntas que planteamos en la introducción de esta investigación: consideramos que pueden y deben coexistir los fotógrafos profesionales y los fotógrafos ciudadanos en la escena mediática, porque juntos aportan más opciones gráficas de un mismo acontecimiento a la opinión pública — siempre y cuando se respete la veracidad de la información que se publica-. En la raíz de nuestro caso de estudio está el fotoperiodismo de calidad, en este sentido, creemos que la calidad fotográfica en las publicaciones es imprescindible, aunque en ocasiones pueda verse afectada dependiendo de cuál sea la fuente gráfica informativa de donde se toma la imagen para acompañar una noticia.

Cuando se trata de un fotógrafo ciudadano no profesional que se pone en contacto con un medio de comunicación y ofrece un material gráfico que ha obtenido con la cámara de su teléfono móvil —en algunos casos, por la inmediatez en que se producen los acontecimientos y la falta de cobertura por periodistas profesionales en el lugar de los hechos-, los medios no tienen más opción que publicar imágenes de baja calidad, para no dejar de informar sobre lo que ya es noticia en las redes sociales — como en el caso citado de Madrid Río en el periódico El Pais-.

Sin embargo, estos son ocasiones excepcionales porque, en la mayoría de los casos, normalmente las fotografías tomadas de las redes sociales, y filtradas por los medios, suelen tener una calidad técnica aceptable. Debido a la evolución tecnológica de los dispositivos de captura fotográfica y a la propia preparación de los fotógrafos, casos como los de Jacobo Méndez Díez y Devin Allen —así como el resto de fotógrafos ciudadanos especializados — aportan una experiencia y multiplicidad que perspectivas que, en nuestra opinión, contribuyen a mejorar la calidad de los medios de comumicación.

\section{Bibliografía}

Ballester, L., Orte, C., y Oliver, J.. L. (2003). Análisis cualitativo de entrevistas. Nómadas (Col). (18), 140-149. Disponible en: https://goo.gl/a1U2Jm 
Castellanos, U. (2011). Manual de fotoperiodismo: retos y soluciones. México: Ed. Universidad Iberoamericana Ciudad de México.

Castells, M. (2009). Comunicación y poder. Madrid: Alianza Editorial.

Crystal, D. (2002). El lenguaje e internet. Madrid: Cambridge University Press.

De Pablos Coello, José Manuel (2006) "Siete leyes del fotoperiodismo". En Caballo Ardila, Diego (ed.) Fotoperiodismo y edición, 255-334. Madrid: Universitas.

Errejón, I., (2011). El 15-M como discurso contrahegemónico, Encrucijadas. Revista Crítica de Ciencias Sociales (2), 120-145. Recuperado de https://goo.gl/Yx6a9E

Espiritusanto, O., y Gonzalo, P. (2011). Periodismo ciudadano: evolución positiva de la comunicación. Madrid: Ariel. Fundación Telefónica.

Fontcuberta, Mar de y Borrat, Héctor, (2006): Periódicos: sistemas complejos, narradores en interacción. Buenos Aires, La Crujía ediciones.

Gillmor, Dan (2007). Dan Gillmory el "Periodismo ciudadano". YouTube (16/11/2007). Disponible en: https://www.youtube.com/watch?v=FbS_Onkfx1U

Hicks, Wilson (1972). What is Photojournalism. En Smith Schuneman, R. (ed.), Photographic Communication. Principles, Problems and Challenges of Photojournalism, New York, Hasting House.

Martínez Moscoso, Dolores Marisa (2002). Fotografía periodística y discurso. Caleidoscopio (11), 135-156. Disponible en: https://goo.gl/utxzKL

Méndez Díez, Jacobo (2018). Entrevista personal realizada por el autor vía telefónica (18 de marzo de 2018).

Molina, M. A. (2011). Demotix, de agencia alternativa a la portada de New York Times. En Blogs. elpais.com (8/12/3012). Disponible en: https://goo.gl/sr7Yvv

Newhall, B., (2002). Historia de la Fotografía. Barcelona: Gustavo Gili.

Ortega Dolz, Patricia; Moñino, Ladislao J. y Pregedo, José (2014). Muere un ultra del Deportivo tras una pelea con radicales del Atlético. En El País (30/11/2014 - 18:17). Disponible en: https://goo.gl/kHzvRj

Puente, S.; Saavedra, G., y Grassau, D. (2011). Análisis de contenido: Ausencia de los valores periodísticos en los medios ciudadanos. Cuadernos.Info, (28), 19-32. DOI: https://doi. org/10.7764/cdi.28.265

Reuters (2003). 'Los Angeles Times' despide a un fotógrafo por manipular una imagen para añadirle dramatismo. En El Mundo.es (03/4/2003). Disponible en: https://goo.gl/JtzTNs

Tirado Pascual, N. (2016): Corrupción y fuentes informativas en medios tradicionales y nativos 
digitales. Miguel Hernández, Communication Journal (7), 257-285. DOI: http://dx.doi.org/10.21134/ mhcj.v0i7.117

Ximénez de Sandoval, Pablo (2017). 'El argentino’ que grabó el primer vídeo viral de la historia. En El País (25/5/2017). Disponible en: https://goo.gl/MpmxWg

Yuste, M. (2018). Las cifras de Internet. En España el 85\% de la población está conectada. En Expansión (1/2/2018). Disponible en: https://goo.gl/VR9wNG

\section{Anexo}

\section{Entrevista realizada a Jacobo Méndez vía telefónica el 15 de Marzo de 2018}

\section{- ¿Qué tipo de fotógrafo te consideras y cómo defines la foto que hiciste?}

Empecé cuando tenía 19 años con la fotografía de prensa, para mí es una actividad más de las que hago, dibujo, pinto y hago fotografías, algo que va conmigo siempre, pero a nivel profesional, solo al principio de mi juventud me he dedicado a ella.

Sobre mi fotografía que fue portada de El País, no sé cómo la definiría, sólo sé que vi, sentí, hice y lo demás lo dice la foto. No había ninguna intención más que lo que hago siempre, fotografiar por placer, buscando el momento, buscando el equilibrio, la composición, en fin, todas esas cosas que me preocupan; no me preocupaba que la foto fuera a ser conocida ni mucho menos. De hecho, de la serie de fotografías que hice, fue al llegar a casa cuando me di cuenta de la foto.

\section{— ¿Qué cámara utilizaste para realizar la fotografía?}

Utilicé una Canon 20D, es una Canon vieja digital. Yo pasé del analógico al digital comprando esa cámara de segunda mano, la foto en cuestión la realicé con un objetivo $50 \mathrm{~mm}$. Me gusta fotografiar con un único objetivo, porque si ya tienes que pensar bastante para hacer una foto y éste te lo da, me parece que es bonito estar limitado y salir con un objetivo y decir: "bueno, me lo voy a montar con este".

\section{— ¿Tiene algún retoque la fotografía que hiciste?}

No hay nada, no hay corte, ni enderezado, ni nada, es tal cual, excepto el cambio de color a blanco y negro.

\section{- ¿Recuerdas las características técnicas de la foto?}

Creo que tenía un ISO 100 porque hacía Sol y tenía el diafragma muy cerrado (1/8), una velocidad alta (de hecho están todos los planos enfocados) y tenía abundancia de luz. Pero tampoco me gusta hacer ráfagas; para hacer cada foto, me paro, me la pienso y la hago, la intuyo y la hago rápido.

\section{- ¿Descríbeme el proceso para hacer la foto?}

No iba para participar activamente de la acampada, yo iba a hacer fotos por placer, para mí. 
Al día siguiente eran las elecciones y estaba el ambiente "caldeadito", me fijé en un grupo de jóvenes que iban con la placa de la plaza y me fui detrás de ellos. Y cuando vi que iban a empezar a encaramarse en la pared, empecé a hacerles fotos.

\section{$-{ }_{¿}$ Crees que la casualidad y la oportunidad juegan en la fotografía que hiciste?}

Creo que son un montón de factores juntos, porque sí es casualidad que fuera ese día; pero también la foto la buscas, creo que hay una intención cuando haces una foto, tus ojos están pendientes de lo que pasa. Sí que fueron varios factores, como que el día era histórico, pillé el momento en el que los chavales se disponían para ir hacía allí y tuve el acierto de seguirlos y ver qué iban a hacer; y luego, cuando vi que subían seguí el proceso e hice unas cuantas fotos. Cuando ya estaba arriba, me retiré un poco para coger a la gente que había delante también y me pareció interesante. Era una composición bastante renacentista, casi barroca.

\section{- ¿Vives de la fotografía, o has dejado de vivir de ella?}

He dejado de vivir de ella. Yo vivía con mi padre en el Salvador, me críe toda mi infancia y adolescencia en el Salvador. Había vivido la Guerra Civil, las habíamos pasado canutas allí. Mi padre era publicista y fotógrafo, hice con mi padre mucho laboratorio y mucho blanco y negro que me encantaba. Hacía fotografía para prensa, estaba en nómina y si ocurría algún suceso, iba con la camarita para hacer las fotos que se publicaban al día siguiente en el periódico, eran fotos testimoniales.

\section{- ¿Qué opinas del periodismo?}

Siempre me intereso, siempre me había gustado mucho, lo que pasa es que a veces pienso que antes había más calidad a la hora de hacer las cosas; ahora hay tanta, que ves verdaderas barbaridades en boca de periodistas que dices: “¿cómo es posible que no sepan?".

\section{$-¿$ ¿Te consideras fotoperiodista?}

No. Yo soy fotógrafo, por placer, por amor al arte, igual que pinto igual que modelo, aunque la fotografía de prensa siempre me ha encantado. Pero me parece muy vanidoso, meterme en el grupo de fotoperiodistas solamente por haber recibido un premio. Creo que detrás de un fotoperiodista profesional hay mucho esfuerzo, mucha carrera, muchas horas de calle. Para mí la fotografía es un gusanillo que da tumbos y siempre ha estado conmigo, aunque a nivel profesional no seguí.

\section{- ¿Cuál fue el proceso que siguió la fotografía que hiciste hasta ser conocida?}

Tenía aproximadamente 7 fotos de ese momento, a mí no me gusta coleccionar muchas fotografías. No sufro del síndrome de Diógenes de la fotografía. Tal vez porque empecé joven en la antigua escuela, los carretes valían dinero y tenías que pensar cómo hacer cada foto. También es un ejercicio muy bueno. Igual que con el objetivo de la cámara, salir con uno solo y decir: "Con esto, a ver qué hago". Cómo vengo del analógico yo no tenía ninguna plataforma en internet, tenía Facebook y Twitter de manera poco activa; pero no tenía ninguna web con fotos, ni siquiera usaba Flickr. 
Pensé que era una foto interesante, porque definía un momento muy bonito y muy importante y dije: "la quiero compartir". La subí primero a Facebook comentando que no me gustaban mucho las fotos en formato vertical, pero como vi que no tuvo mucha repercusión, se me ocurrió subirla a Twitter. Antes le escribí a un conocido tuitero con miles de seguidores llamado@Kurioso y le pregunte qué le parecía la foto y si me ayudaría a compartirla en su canal, y él aceptó encantado porque le parecía una excelente imagen. Antes de que la foto fuera retuiteada, primero me cree una cuenta en Flickr y la guardé en este banco de imágenes, luego copié el enlace de la foto y lo publiqué en Twitter, cuando la imagen fue retuiteada por @Kurioso, de repente empezaron a hacerme menciones en Twitter, muchas visitas en Flickr, y en cuestión de una hora tenía 10.000 visitas. Había una especie de reconocimiento por la aportación que había hecho al momento.

\section{- ¿Cómo se puso en contacto el periódico El País contigo?}

Fue todo por Twitter a través de menciones. Se habían puesto en contacto conmigo varios periódicos, entre ellos tenía un mensaje de El País, que decía: "Jacobo, por favor, llama a este teléfono que estamos buscándote"; y cuando llamé hablé con la redactora jefe —que en ese momento era Marisa Flores_ que se alegró de mi llamada porque el director quería mi foto de portada al día siguiente. Me dijeron que si quería colaborar con ellos tenía el teléfono para enviarles más fotos para vender, aunque yo seguí mi vida con normalidad.

Al finalizar el año alguien me comentó de los premios Ortega y Gasset, donde envié la foto, y de repente, un día en abril, me llamaron, ya ni me acordaba, y me dijeron: "Jacobo te llamo de El País, enhorabuena, has ganado el premio, luego te llamarán para pedirte todos los datos y para explicarte lo de la entrega del premio".

\section{- ¿Quedaste satisfecho con la remuneración que te pagó El País por la foto?}

Como no tenía ni idea de lo que pagaban, cuando me lo dijeron me sorprendió para mal, y dije, bueno, al ser una portada —3 o 4 columnas creo que era- y pagáis esto; pero al final acepté.

\section{- ¿Qué entiendes por periodismo ciudadano?}

Creo que lo bueno que tienen ahora las redes sociales es que todo el mundo puede aportar algo. En mi caso hice una periodística — aunque no me considero periodista-; pero creo que esa capacidad que tiene ahora la gente de —igual que al que le gusta la música, ahora puede editarse su propio disco (aunque luego no vaya a ningún lado)—; pero creo que esa posibilidad, que antes era tan difícil de participar activamente en cualquier cosa, ahora es posible y me parece estupendo.

\section{— ¿Qué opinas de que las redes sociales nutran los medios tradicionales?}

Creo que les nutren; pero también les corrompen bastante. Ahora hay tal bombardeo de opiniones que, al final, tampoco sabes qué es verdad. También la gente aprovecha las redes sociales para meterse con los demás; no sé, hay un lado muy bonito y otro que me espanta.

\section{- ¿Qué opinas de que fotógrafos como tú participen en este proceso comunicativo?}


Me parece estupendo, todo lo que sea poder expresarse y facilitar la comunicación me parece genial.

\section{- ¿Qué trabajos has hecho?}

Suelo hacer cosas para mí, he hecho alguna exposición, por ejemplo, una de un invierno que pasé en Burgos y me metí en los campos de trigo. Iba casi todos los días buscando composiciones, fue una exposición fotográfica muy personal, muy íntima. Sobre todo quería componer, me tiraba horas y horas, días y días, haciendo fotos en los campos de trigo, algo que parece tan monótono; pero que yo encontraba una maravilla. También hice una exposición en blanco y negro.

\section{- ¿Qué opinas del cambio analógico al digital?}

Era muy bonito, jugabas con el tipo de película, según el grano que quisieras. A mí me parecía genial el proceso de revelado y todo era apasionante. Todavía me cuesta, todavía no me creo la foto hasta que no la veo impresa: la veo muy bonita, pero pienso, son números y son luces, y es que no hay foto. Me encanta verla en papel, recuerdo en el laboratorio cuando veías aparecer la foto en el papel, era una gozada. Para mí verla en papel es necesario, está muy bien lo virtual; pero yo necesito el papel.

\section{- ¿Te cambió en algo el hecho de recibir el premio Ortega y Gasset?}

Mi vida sigue siendo la misma, pero a nivel personal siento una satisfacción de haber tenido la oportunidad de participar de esa manera. También el cariño y la respuesta de la gente, allí donde me entrevistaban era todo positivo; no me he encontrado con ningún momento que no me gustase. Y también satisfacción por que yo empecé en esto y, de repente, a los cuarenta y pico, me encuentro con que he aportado mi granito de arena en algo que me apasiona, y encima que la foto se convirtió en un símbolo. 
MHCJ nº 9 (2) | Año 2018 - Artículo no 12 (127) - Páginas 337 a 357 - mhjournal.org

\section{(c) (1) (2)}

Licencia Creative Commons

Miguel Hernández Communication Journal

mhjournal.org

\section{Cómo citar este texto:}

Juan Carlos Gómez Muñoz, Andrés Ballesteros Palencia (2018): Contenidos gráficos generados por fotógrafos ciudadanos y publicados en los medios. El caso del fotógrafo Jacobo Méndez Díez en El País, en Miguel Hernández Communication Journal, nº9 (2), pp. 337 a 357. Universidad Miguel Hernández, UMH (Elche-Alicante). DOI: http://dx.doi.org/10.21134/mhcj.v0i9.263 